DOI: 10.17707/AgricultForest.62.4.08

\author{
Amani ALAWAMLEH, \\ Ahmad KATBEH-BADER, Naim HASSAN, \\ Ibrahim AL-JBOORY, Anna Maria D'ONGHIA ${ }^{1}$
}

\title{
BIOLOGICAL STUDIES ON THE AFRICAN FIG FLY, ZAPRIONUS INDIANUS GUPTA (DIPTERA: DROSOPHILIDAE)
}

\begin{abstract}
SUMMARY
The African fig fly, Zaprionus indianus Gupta, is a widely distributed polyphagous drosophilid fly of tropical origin. Its occurrence in Jordan was first reported on date palms from the Central Jordan Valley in June 2012. Studies on biological aspects of a fly population collected from Northern Jordan Valley were carried out under laboratory conditions at $25 \pm 1^{\circ} \mathrm{C}, 75 \pm 10 \% \mathrm{RH}$, and $14 \mathrm{~h}$ photoperiod. Mashed banana fruits with dry active yeast of Saccharomyces cerevisiae were used for the first time as a diet for larval and adult stages. The data obtained showed that the average mating period was 2.5 days, the preoviposition period 2.7 days, the oviposition period 42.7 days, incubation period $24.5 \mathrm{~h}$, hatching of eggs was $91.7 \%$, duration of larval stage 7.4 days, pupal stage 6.8 days, adult male life span 42.2 days, adult female life span was 37.7 days. The larval stage had the highest mortality followed by the pupal stage and then the egg stage. The life cycle lasted 13.9 to 23.2 days with an average of 17.9 days. Emerged adult flies showed a sex ratio of 1.0. The obtained results provided basic data that may help in the management of this pest in Jordan.
\end{abstract}

Keywords: Zaprionus indianus, biology, life cycle, laboratory rearing.

\section{INTRODUCTION}

Zaprionus indianus Gupta is a polyphagous drosophilid fly of tropical origin (Pasini and Link, 2011). It successfully colonized the Indian subcontinent more than four decades ago, and more recently South America and North America (Yassin et al., 2008). It was recorded recently for the first time in Jordan (Al-Jboory and Katbeh-Bader, 2012). This species cannot survive at high latitudes and this explains its restriction to tropical and subtropical climates (Karan et al., 1999). Its optimum temperature ranged from 20 to $30^{\circ} \mathrm{C}$ (Amoudi et al., 1993). In Saudi Arabia, the mean generation life cycle was recorded as 22.4

\footnotetext{
${ }^{1}$ Amani Alawamleh, Anna Maria D'onghia, CIHEAM/Mediterranean Agronomic Institute of Bari, Via Ceglie 9, 70010 Valenzano (Ba), ITALY, Plant Wealth Laboratories Directorate, Ministry of Agriculture, Amman, JORDAN, Ahmad Katbeh-Bader, (corresponding author: Ahmadk@ju.edu.jo), Department of Plant Protection, Faculty of Agriculture, The University of Jordan, Amman 11942, JORDAN, Naim Hassan, Research and Development, Russell IPM Ltd, Chester, UNITED KINGDOM, Ibrahim Al-Jboory, Department of Plant Protection, College of Agriculture, University of Baghdad, IRAQ.

Paper presented at the $7^{\text {th }}$ International Scientific Agricultural Symposium "AGROSYM 2016".

Notes: The authors declare that they have no conflicts of interest. Authorship Form signed online.
} 
days at $25^{\circ} \mathrm{C}$ which was shorter than that recorded at $30^{\circ} \mathrm{C}$ (Amoudi et al., 1991), while in Brazil it was at an average of 13 to 20 days (Stein et al., 2003).The number of generations/year varies from 12 to 16 (Karan et al., 2000; Setta and Carareto, 2005; Nava et al., 2007). Field and laboratory studies on Indian populations showed that $Z$. indianus overwinters in the egg stage and to a few extents as pupae. Eggs remain in quiescent stage until the weather become warmer.

There are no biological data related to the fly populations from Jordan. Therefore, studies on some of its biological aspects for a Jordanian population collected from Jordan Valley $220 \mathrm{~m}$ below sea level were carried out under laboratory conditions. Obtained data will be helpful for the establishment of efficient management strategies against the fly populations.

\section{MATERIAL AND METHODS}

A stock colony of $Z$. indianus was started with 200 adults collected from sour orange orchard (Citrus aurantium L.), Northern Jordan Valley $\left(32^{\circ} 25^{\prime} 54^{\prime \prime} \mathrm{N} /\right.$ $35^{\circ} 35^{\prime} 30 " \mathrm{E}, 213 \mathrm{~m}$ below sea level) in March 2013. The flies were maintained in the laboratory at a temperature of $(25 \pm 1)^{\circ} \mathrm{C}$, relative humidity of $(75 \pm 10) \%$ in plastic jars $(120 \times 160 \mathrm{~mm})$ capped with a fine cloth. Small plastic plates $(55 \mathrm{x}$ $25 \mathrm{~mm}$ ) containing mashed banana fruits seeded with dry and active yeast Saccharomyces cerevisiae were placed inside the jar for adult feeding and oviposition and were renewed every 3-4 days. All biological experiments were conducted in an incubator at $25 \pm 1^{\circ} \mathrm{C}$, relative humidity of $(75 \pm 10) \%$, and $14 \mathrm{hr}$ photoperiod. One virgin female and one male (one day old) were randomly taken to be the parents of experimental flies, and placed into a plastic jar $(80 \times 75 \mathrm{~mm})$. The procedure was repeated six times. The plastic plates were inspected daily under a stereomicroscope at 40X. Duration of premating, mating, pre oviposition, oviposition and post oviposition periods were recorded. Ten eggs $(\leq 2 \mathrm{hr}$ old $)$ were transferred to each plate ( $30 \times 25 \mathrm{~mm}$, containing mashed banana fruits) for a total of 60 eggs. Observations were performed at $6 \mathrm{hr}$ intervals. Duration of incubation, fertility and percentage of hatched larvae in each plate were recorded. The hatched larvae (one day old) were transferred in groups of ten larvae to 6 plastic plates $(55 \times 25 \mathrm{~mm})$ containing mashed banana fruits (a total of 60 larvae). Each plate was placed in a plastic jar $(80 \times 75 \mathrm{~mm})$ capped with a fine cloth and placed in the incubator.

Observations were performed daily and the duration of each larval instar and percentage of pupae in each plate were recorded. Pupae (one day old) were transferred in groups of ten to six plastic plates $(55 \times 25 \mathrm{~mm})$ containing moistened filter paper on the bottom of the plate (a total of 60 pupae). Each plate was placed in a plastic jar $(80 \times 75 \mathrm{~mm})$ capped with a fine cloth and placed in the incubator. Observations were performed daily and the duration of the pupal stage and percentage of emerged adults in each plate were recorded. Female to male ratio was recorded. Longevity of sexually active flies was studied by placing ten couples of virgin flies (one day old) each pair into a glass vial ( $25 \mathrm{x}$ 
$95 \mathrm{~mm}$ ) capped with cotton, and transferred to new vials with fresh media until their death, at intervals of 2-3 days to keep the quality of the media and to avoid toxic effect of metabolites. The same procedure was followed for longevity of sexually inactive flies by placing them separately. Vials were autoclaved and contained Formula 4-24 Instant Drosophila medium (Carolina Biological Supply Company, USA). The used vials were washed in a $10 \%$ chlorine bleach solution each time renewing the media. Vials were inspection daily and the dead flies were removed. Longevity of adult flies were recorded. For all investigated parameters, simple mean values were calculated.

\section{RESULTS AND DISCUSSION}

All studied biological parameters are shown in Table 1. Our results represent the first data of biological features of Jordanian populations of $Z$. indianus which showed variations in some biological characteristics when compared to other fly populations from different geographical areas.

The mating duration in Jordanian populations of the fly was close to that obtained by Müller et al. (2012) which ranged between $18 \mathrm{~s}$ to 6 min and $56 \mathrm{~s}$, with average of $2 \mathrm{~min}$ and $16 \mathrm{~s}$ ). The obtained premating and preoviposition durations were similar because the mated females laid eggs after mating due to availability of ideal oviposition substrate.

Table 1. Parameters of Z. indianus

\begin{tabular}{|c|c|c|}
\hline Parameter & Range & $\overline{\mathrm{x}}$ \\
\hline Premating duration (day) & $2-4$ & 2.67 \\
\hline Mating duration (min.) & $2.12-3.02$ & 2.48 \\
\hline Preoviposition duration (day) & $2-4$ & 2.67 \\
\hline Oviposition duration (day) & $16-63$ & 42.67 \\
\hline Postoviposition duration (day) & $0-10$ & 6.00 \\
\hline Sex ratio (F/M) & $4-6 / 3-6$ & $4.5-4.3$ \\
\hline Incubation period (hr) & $22-28$ & 24.50 \\
\hline Fertility \% & $80-100$ & 91.67 \\
\hline Larval duration (day) & $5-10$ & 7.36 \\
\hline Larval viability \% & $50-100$ & 75.00 \\
\hline Pupal duration (day) & $6-8$ & 6.83 \\
\hline Pupal viability \% & $70-100$ & 88.33 \\
\hline Longevity of sexually active female flies (day) & $4-79$ & 37.70 \\
\hline Longevity of sexually active male flies (day) & $12-77$ & 42.20 \\
\hline Longevity of sexually inactive female flies (day) & $14-35$ & 26.00 \\
\hline Longevity of sexually inactive male flies (day) & $5-78$ & 37.20 \\
\hline
\end{tabular}

Z. indianus premating, mating, preoviposition, oviposition, postoviposition durations ( $\mathrm{n}=6$ ), egg incubation period, fertility percentage, larval and pupal duration and viability, sex ratio $(n=60)$, and longevity of sexually active and sexually inactive adult flies $(n=10)$.

The preoviposition duration (2-4 days) was very close to that obtained at $25^{\circ} \mathrm{C}$ by Pires et al. (2008) and lower than that recorded by Amoudi et al., (1991) which ranged from 5 to 8 days in Saudi populations at the same experimental 
temperature. The duration of oviposition and postoviposition recorded in the present study were 16-63 and 0-10 days, respectively which were similar to Saudi populations (9-62 and 0-12 day of oviposition and postoviposition, respectively, Amoudi et al., 1991). However, in the Brazilian populations oviposition period lasted $14-98$ day at $25^{\circ} \mathrm{C}$ (Setta and Carareto, 2005). The incubation period was ranged from $22-28 \mathrm{hr}$ and fertility from $80-100 \%$. In comparison, Amoudi et al. (1991) reported higher incubation period (28-60 hr) and lower fertility (53-92\%). While Stein et al. (2003) reported an incubation period of 1-1.5 day and viability of $88.89 \%$ which are similar to our results. In Saudi Arabia, Amoudi et al. (1991) studied the effect of different temperatures on the life cycle of $Z$. indianus, and recorded duration of 4-11 days for the larval development and 5-9 days for pupa development at $25^{\circ} \mathrm{C}$ which was similar to our recoded values. In Brazil, Nava et al. (2007) reported a larval duration of 8.211.3 day and a pupal $3.4-5.5$ day at $25^{\circ} \mathrm{C}$. Matavelli et al. (2013) reported a pupal duration of 4-6 days. These results show higher values of larval duration and lower values of pupal duration in comparison with values obtained in our study. The differences in larval duration can be attributed to the composition of the diet provided to the larva which was Formula 4-24 instant Drosophila medium in study performed by Amoudi et al. (1991), Vilela's diet in Brazilian study performed by Nava et al. (2007) and artificial diet based on banana in another Brazilian study conducted by Matavelli et al. (2013), while mashed banana fruits with dry and active yeast Saccharomyces cerevisiae for larval development in our study.

Brazilian populations of the fly showed mean larval viability of $76 \%$ and mean pupal viability of $87.88 \%$ (Stein et al., 2003) which were very close to our findings. Also Saudi populations of the fly showed similar mean pupal viability to our findings which was $89 \%$, but higher mean larval viability which was $88 \%$ (Amoudi et al., 1991). On the other hand, the mean mortality in egg, larval, and pupal stages recorded in the present study were 8.33, 25, and $11.67 \%$, respectively. . Similar results were obtained in Brazil as 11.11, 24, and $12.12 \%$ representing the mean mortality in egg, larval, and pupal stages, respectively (Stein et al., 2003).

The evaluation of the number of females and males emerged from 60 pupa was obtained by identifying the sex ratio (F/M) which was 1.04 . Similar results were recorded in Brazil as 1.32 and 1.11 which represents higher numbers of females than males (Setta and Carareto, 2005, Matavelli et al., 2013), which confirms our findings.

The mean duration of life cycle of $Z$. indianus at $25^{\circ} \mathrm{C}$ recorded in our study (17.9 days with a range of 13.9 - 23.2 days) was similar to that reported in Brazil by Setta and Carareto (2005) at the same experimental temperature, which was 18.5 day with a range of 15-25 day, also to that reported in Brazil too by Stein et al. (2003) who recorded the mean life cycle as 16.78 day with a range of 13-23.50 day at the same temperature. 
The exception was observed when we compared with Saudi populations of the fly, the mean life cycle recorded at $25^{\circ} \mathrm{C}$ by Amoudi et al. (1991) was 22.4 days and is considered higher than that we obtained, despite being at the same geographical area; they had variable latitude and longitude which may contribute to such differences. The viability data and total development time results agree with findings reported by Nava et al. (2007) who found that the temperatures near to $28^{\circ} \mathrm{C}$ are the thermal optimum for egg-adult development, allowing shorter development time and high viability. Furthermore, these results indicated that the diet used in this experiment was convenient for rearing this species and achieving successful development under the laboratory conditions.

The mean longevity of sexually active female flies obtained in our study was lower than those recorded by Amoudi et al. (1991) for Saudi population of $Z$. indianus which was 50.4 days, while the mean longevity of sexually active male flies obtained in our study has the same value of that recorded by Amoudi et al. (1991) which was 42.2 days.

Döge et al. (2009) studied the effect of marking virgin adult flies of South American strains of $Z$. indianus with marker pen ink on persistence of marks and longevity at $25^{\circ} \mathrm{C}$ and using cornmeal media for rearing adult flies. They obtained mean longevity of non-marked virgin females of 32.9 day which was similar record as in our study, and mean longevity of non-marked virgin males of 18.7 day which was lower than we recorded..

However, studies of longevity of sexually active and inactive flies carried out by Setta and Carareto (2005) for Brazilian population, which were reared on banana-agar media at $25^{\circ} \mathrm{C}$, were found to be higher than that obtained for the Jordanian population of the fly. Also it was observed that sexually active and inactive females lived longer than males, while results from our study showed that females died earlier than males.

Pires et al. (2008) evaluated the longevity of sexually active adult flies from two geographic strains of Brazilian population, the Jaboticabal strain and the Valinhos strain at $25 \pm 2{ }^{\circ} \mathrm{C}$. Our results are in line with the findings of Valinhos strain which had males mean longevity of 53.51 day and females mean longevity of 33.53 day.

Females had a shorter life cycle than males in both cases, due to the oviposition process which was observed in sexually active and inactive female flies and it may cause depletion of protein and energy for egg production. Also we found that the mean longevity of sexually active female flies (37.7 day) is higher than that of sexually inactive female flies (26.0 day), despite they laid fertile eggs at high rate. These differences in longevity values could be due to the experimental conditions such as the culture medium used for feeding adult flies, controlled temperature, photoperiod and uncontrolled relative humidity.

In general, these overall variations in biological parameters from our results could be related to different photoperiod, relative humidity and type of diet provided to parental adult flies for feeding and oviposition. In addition, different fly populations from different geographical areas were studied; flies 
were collected in Saudi Arabia from Taif area which is about $1600 \mathrm{~m}$ above sea level (Amoudi et al., 1991), while flies in the present study were collected from Jordan Valley about $220 \mathrm{~m}$ below sea level.

It will be interesting to verify the lower temperature threshold for development and the thermal constant (Degree-Days) values for the egg, larval and pupal stages, which can be used when applying control measures during fruits storage and exportation, especially fig fruits. Finally, there is a need of further research on the ecology of $Z$. indianus to investigate its seasonal dynamics.

\section{CONCLUSIONS}

The African fig fly was successfully reared under laboratory conditions at $25 \pm 1^{\circ} \mathrm{C}, 75 \pm 10 \% \mathrm{RH}$, and $14 \mathrm{~h}$ photoperiod on mashed banana fruits with dry active yeast for the first time. Most life cycle parameters were comparable to other populations of the fly in other countries such as Saudi Arabia and Brazil. However, some differences were found which could be due in part to differences in experimental conditions and diet components. The results could be helpful in the management of this pest in Jordan.

\section{ACKNOWLEDGMENTS}

We thank institutions that made possible this M.Sc. work: Ministry of Agriculture/Jordan and Mediterranean Agronomic Institute of Bari/Italy (CIHEAM-MAIB). This work was supported by MAIB grants. Also thanks to the National Center for Agricultural Research and Extension (NCARE)/Jordan for the technical support.

\section{REFERENCES}

Al-Jboory I. J. and Katbeh-Bader A. (2012). First record of Zaprionus indianus (Gupta, 1970) (Drosophilidae: Diptera) in Jordan. World Applied Sciences Journal, 19(3): 413-417.

Amoudi M. A., Diab F. M. and Abou-Fannah S. S. M. (1991). Zaprionus indianus (Diptera: Drosophilidae) in Saudi Arabia and the effect of temperature on the life cycle. Journal of King Saud University, 3(2): 111-121.

Amoudi M. A., Diab F. M. and Abou-Fannah S. S. M. (1993). The influence of low temperature on development, adult longevity and productivity of Zaprionus indianus Gupta (Diptera: Drosophilidae). Journal of King Saud University, 5(2): 263-274.

Döge J. S., Hochmüller C. J. C., Valente V. L. S. and Tidon R. (2009). Potential use of marker pen ink as a marking method for drosophilids. Drosophila Information Service, 92: 123-126.

Karan D., Dubey S., Moreteau B., Parkash R. and David J. R. (2000). Geographical clines for quantitative traits in natural populations of a tropical drosophilid: Zaprionus indianus. Genetica, 108: 91-100.

Karan D., Moreteau B. and David J. R. (1999). Growth temperature and reaction norms of morphological traits in a tropical drosophilid: Zaprionus indianus.Heredity, 83: 398-407. 
Matavelli C., José Zara F. and José Von Zuben C. (2013). Post-embryonic development in Zaprionus indianus (Diptera: Drosophilidae). Annals of the Entomological Society of America,106(6): 779-787.

Müller M. J., Mendonça M. P., Oliveira I. R., Oliveira L. P. L., Valente V. L. S. and Valiati V. H. (2012). Courtship behavior of Zaprionus indianus (Gupta) (Diptera: Drosophilidae) from populations colonizing South America. Neotropical Entomology, 41: 112-120.

Nava D. E., Nascimento A. M., Stein C. P., Haddad M. L., Bento J. M. S. and Parra J. R. P. (2007). Biology, thermal requirements, and estimation of the number of generations of Zaprionus indianus (Diptera: Drosophilidae) for the main fig producing regions of Brazil. Florida Entomologist, 90(3): 495-501.

Pasini M. P. B. and Link D. (2011). Efficiency of different traps to capture Zaprionus indianus (Diptera: Drosophilidae) in fig orchard in Santa Maria county, Rio Grande do Sul state, Brazil. International Research Journal of Agricultural Science and Soil Science, 1(8): 349-354.

Pires D. J., Bélo M. and Barbosa J. C. (2008). Life history estivatives in two geographic strains of Zaprionus indianus Gupta, 1970 (Diptera: Drosophilidae). Biodiversidade, 7(1): 42-55.

Setta N. and Carareto C. M. A. (2005). Fitness components of a recently-established population of Zaprionus indianus (Diptera, Drosophilidae) in Brazil. Iheringia Série Zoologia, 95(1): 47-51.

Stein C. P., Teixeira É. P. and Novo J. P. S. (2003). Aspectos biológicos da mosca do figo, Zaprionus indianus Gupta,1970 (Diptera: Drosophilidae). Entomotropica, 18(3): 219-221.

van der Linde K. (2010). Zaprionus indianus: species identification and taxonomic position. Drosophila Information Service, 93: 95-98.

Yassin A., Capy P., Madi-Ravazzi L., Ogereau D. and David J. R. (2008). DNA barcode discovers two cryptic species and two geographical radiations in the invasive drosophilid Zaprionus indianus. Molecular Ecology Resources, 8: 491-501. 